\title{
Features of procedural characteristics of life elections of young people depending on types of personal maturity/immaturity
}

\author{
Yuliya Rashchupkina ${ }^{1 *}$, Yuliya Tushnova $^{1}$, Dalen Alasaad ${ }^{2}$ \\ ${ }^{1}$ Don State Technical University, 344000 Rostov-on-Don, Russian Federation \\ ${ }^{2}$ Al-Baath University, Faculty of education, 00963 - 031, Homs, Syrian Arab Republic
}

\begin{abstract}
The article presents the results of a study of the procedural characteristics of life choices by young people. The choices of life are choices of lifestyle, career and other significant. For each of the life choices, the process characteristics are considered, which reflect confidence, independence, awareness of choice and expressed in the selfesteem of respondents. The procedural characteristics are analyzed in connection with the maturity of the personality, which determines their specificity for each of life's choices. Personal maturity is considered as a specific phenomenon, the structure of which is reflected by the integrity of interconnected components, including value-motivational, emotionalvolitional, reflective, operational components. Types of personality maturity are distinguished on the basis of the content of each of the components and are considered in the continuum "personality maturity personality immaturity". Empirically studied and disclosed are the features of the process characteristics of each of the life choices of young people, depending on the severity and types of their personal maturity. It is empirically established that the severity of the procedural characteristics of each of the life choices is due to the type of maturity or immaturity. Each of the life choices of young people was considered in the context of maturity.
\end{abstract}

\section{Introduction}

A person's life path is a series of various choices that a person makes all the time. These elections can concern various spheres and can be carried out at different levels: psychological, social and others. The choice of a person has powerful driving and guiding forces, regulatory capabilities. That is why any choice is personally significant and to one degree or another affects the future life path of the individual. The choice constituting the direction and nature of the further development of the personality, its fate and life in general, can be defined as a life choice.

In a scientific interpretation, life choice is understood as a process and the result of comparing homogeneous alternatives, ending with a conscious development by a person

\footnotetext{
* Corresponding author: yulk-r@mail.ru
} 
(based on his values and motives) of decisions that are subsequently realized in any area of his life [4]. One of the main life choices can be choices of lifestyle, career and significant other person, which are interconnected. So, choosing a career, the personality thereby chooses a further lifestyle, a path of development [1;3]. Along with this, the person chooses an authoritative significant other person, potentially affecting its development, behavior, lifestyle [5].

An analysis of the scientific and psychological literature showed that the characteristics of the life choices that are required for an effective, mature, meaningful choice are procedural and productive. The procedural characteristics reflect the conscious inclusion of the personality, the measure of its independence and confidence in the course of the choice, the effective ones - the content and the spatio-temporal perspective of the choice. This article discusses the procedural characteristics of the life choices of an individual - career, lifestyle and other significant. How confidently, independently and consciously makes his choice, a person can judge its maturity.

\section{Procedure and research methods}

A comprehensive study of the presented life choices, the severity of their procedural characteristics and their relationship with the gender of subjects characterized by different types of personality maturity is practically absent. In this regard, the purpose of this study was to study the procedural characteristics of the life choices of young people with different types of personality maturity. The subject of the study was the choice of lifestyle, career and other significant. The object of the study was 269 respondents aged 20 to 37 years. Research methods and techniques: questionnaire (modified questionnaires S.T. S.T. nonparametric statistics methods (Friedman, Wilcoxon, Mann-Whitney criteria $(p<0.05)$ ), quartile procedure, binomial criterion.

\section{Discussion of the results}

In this study, personality maturity is understood as a complex education represented by the hierarchy of values and motivations of individualization and socialization formed at the moment of the subject's development, expressed self-regulation by will, developed selfawareness, high arbitrary behavior along with pronounced social adaptation. Therefore, personality maturity has a four-component structure, including value-motivational, emotional-volitional, reflexive, operational components, and is represented by the content of these components. As a result of factor analysis, the types of maturity were distinguished empirically and described, differing in the leading content of the dominant component, interconnected with the contents of other components. As a result, groups of respondents with their respective types of maturity were distinguished: group 1 - "high social adaptation at the cost of internal control"; Group 2 - "awareness of their social roles"; 3 group - "selfexpression"; Group 4 - "emphasis on the values of individualization"; 5th group "pronounced reflexivity"; 6th group - "the significance of creativity". Given the content and severity of personality traits inherent in the respondents of the first three groups, their types of maturity were assigned to the pole "personality maturity", other types of maturity to the pole "personality immaturity". The 7th group consisted of respondents characterized by personality infantility, who were also assigned to the pole "personality immaturity" [2].

\section{Conclusions}


The results indicate that the severity of individual characteristics of respondents' life choices can either coincide or differ depending on the types of "mature / immature" personality and types of personality maturity / immaturity of young people. "Mature", as well as "immature" young people demonstrate high confidence in choosing a career, high independence and awareness - in choosing the ideal lifestyle.

To select a significant other, the features of its characteristics are determined by the personality maturity / immaturity of the subjects. For personally mature youth, this choice is characterized by high awareness along with low independence, for personally immature high independence along with low awareness (Table 1).

Table 1. Significant differences in the severity of the process characteristics of life elections in personally mature and personally immature young people (by the Mann-Whitney criterion, $p \leq 0,05$ ).

\begin{tabular}{|c|c|c|c|c|}
\hline \multirow{2}{*}{$\begin{array}{l}\text { Procedural } \\
\text { characteristics }\end{array}$} & \multirow{2}{*}{$\begin{array}{l}\text { Varieties of life } \\
\text { choices }\end{array}$} & \multicolumn{2}{|c|}{ Groups of young people } & \multirow{2}{*}{$\begin{array}{l}\text { Summary of } \\
\text { differences }\end{array}$} \\
\hline & & "Mature" & "Immature" & \\
\hline \multirow[t]{2}{*}{ Confidence } & $\begin{array}{l}\text { Choice of Ideal } \\
\text { Lifestyle }\end{array}$ & 7,4 & 7,1 & Identified \\
\hline & $\begin{array}{l}\text { Significant other } \\
\text { choice }\end{array}$ & 7,3 & 6,7 & Identified \\
\hline \multirow[t]{3}{*}{ Independence } & $\begin{array}{l}\text { Choice of Ideal } \\
\text { Lifestyle }\end{array}$ & 8,8 & 8,6 & Identified \\
\hline & & \multicolumn{2}{|c|}{$\begin{array}{l}\text { Groups of Personally "Mature” Young } \\
\text { People }\end{array}$} & \\
\hline & & $\begin{array}{l}\text { "Awareness of } \\
\text { their social roles" }\end{array}$ & "self-expression" & \\
\hline Independence & Career choice & 7,3 & 7,9 & Identified \\
\hline \multirow[t]{3}{*}{ Mindfulness } & $\begin{array}{l}\text { Significant other } \\
\text { choice }\end{array}$ & 7,16 & 7,24 & Identified \\
\hline & & \multicolumn{2}{|c|}{$\begin{array}{l}\text { Groups of Personally Immature Young } \\
\text { People }\end{array}$} & \\
\hline & & $\begin{array}{l}\text { "Expressed } \\
\text { reflexivity " }\end{array}$ & $\begin{array}{l}\text { " emphasizing values } \\
\text { individualization " }\end{array}$ & \\
\hline \multirow[t]{2}{*}{ Independence } & $\begin{array}{l}\text { Significant other } \\
\text { choice }\end{array}$ & 6,8 & 6,7 & Identified \\
\hline & & "self-expression" & $\begin{array}{l}\text { " emphasizing values } \\
\text { individualization " }\end{array}$ & \\
\hline \multirow[t]{2}{*}{ Mindfulness } & Career choice & 6,8 & 5,9 & Identified \\
\hline & & $\begin{array}{l}\text { "Expressed } \\
\text { reflexivity " }\end{array}$ & $\begin{array}{l}\text { " personal } \\
\text { infantility " }\end{array}$ & \\
\hline \multirow[t]{2}{*}{ Independence } & Career choice & 6,8 & 7,4 & Identified \\
\hline & & $\begin{array}{l}\text { "Expressed } \\
\text { reflexivity " }\end{array}$ & "self-expression" & \\
\hline Mindfulness & $\begin{array}{l}\text { Significant other } \\
\text { choice }\end{array}$ & 6,5 & 7 & Identified \\
\hline
\end{tabular}

Taking into account the results of comparing each of the characteristics for one choice or another, it was established that the choice of the ideal lifestyle by the respondents of the 1 st group is characterized by high confidence, independence and awareness; their choice of career - high confidence and awareness, individually variable indicators of independence; their choice of a significant other - high confidence, independence and awareness. Respondents are characterized by high confidence, first of all, when choosing a career, high 
independence and awareness when choosing the ideal lifestyle. Thus, in subjects characterized by the type of "high social adaptation at the cost of internal control" of maturity, the severity of the procedural characteristics of their choices, lifestyle ideals, and significant others makes it possible to classify these choices as mature. The severity of the process characteristics of career choice by respondents in this group allows us to call this choice moderately mature.

The choice of the ideal lifestyle by young people of the 2nd group is characterized by high confidence, low independence and individually variable indicators of awareness; their choice of a career - individually variable indicators of confidence, low independence and high awareness; their choice of a significant other - high confidence and independence, individually variable indicators of awareness. In other words, in subjects characterized by the type of personal maturity "awareness of their social roles", the severity of the process characteristics of each of the life choices makes it possible to attribute their choices of the ideal lifestyle and career to immature, and the choice of a significant other to the moderately mature.

The choice of the ideal lifestyle by subjects of the 3rd group is characterized by high independence and awareness, individually variable indicators of confidence; their choice of career - high confidence, individually variable indicators of independence and awareness; their choice of a significant other - high confidence and independence, individually variable indicators of awareness. Respondents are characterized by high confidence, especially when choosing a career, high independence in choosing the ideal lifestyle. Consequently, in subjects characterized by the type of personal maturity, "self-expression", the severity of the procedural characteristics of the choices of the ideal lifestyle and significant other allows you to call these choices moderately mature, their choice of career attributed to immature.

In general, personally mature young people confidently carry out each of the life choices, demonstrate independence mainly when choosing the ideal lifestyle and meaningful other, and awareness when choosing the ideal lifestyle and career. Thus, taking into account the severity of the procedural characteristics of each of the life choices by personally mature young people, the most mature is their choice of lifestyle ideal, moderate maturity is their choice of career and significant other.

The choice of the ideal lifestyle by young people of the 4th group is characterized by low confidence, high independence and individually variable indicators of awareness; their choice of career - individually variable indicators of confidence and awareness, high nonindependence with an orientation to a favorable set of circumstances; their choice of a significant other - individually variable indicators of confidence, high non-independence with an orientation to a favorable combination of circumstances and low awareness. Thus, in subjects characterized by the type of personality immaturity, "emphasizing the values of individualization", the specificity of the expressiveness of the procedural characteristics of the choices of the ideal lifestyle, career, and significant other brings these choices closer to immature.

The choice of an ideal lifestyle by the respondents of group 5 is characterized by individually variable indicators of confidence, high independence and awareness; their choice of career - high confidence, awareness and lack of independence with an orientation to a favorable combination of circumstances; their choice of a significant other individually variable indicators of confidence, high independence and low awareness. Consequently, in subjects characterized by the type of personality immaturity, "pronounced reflexivity", the severity of the procedural characteristics of their choices of the ideal lifestyle and career, allow these selections to be moderately mature, and the choice of a significant other to immature. 
The choice of the ideal lifestyle by subjects of the 6th group is characterized by individually variable indicators of confidence and awareness, high independence; their choice of career - individually variable indicators of confidence and independence, high awareness; their choice of a significant other - individually variable indicators of confidence and independence, low awareness. Thus, in subjects characterized by the type of personal immaturity, the "significance of creativity", the severity of the procedural characteristics of the choices of the ideal lifestyle, career, and significant other allows us to call these choices immature.

Each of the life choices by young people of the 7th group is characterized by individually variable indicators of confidence and awareness. Also, their choice of an ideal lifestyle is characterized by high independence; their choice of career - high non-selfsufficiency with an orientation to the help of other people; their choice of a significant other - high non-independence with an orientation either to the help of others or to a favorable combination of circumstances. Consequently, in subjects characterized by personality immaturity, the specificity of the procedural characteristics of each of the life choices makes it possible to classify their choices as immature.

In general, personally immature young people show high severity of individual procedural characteristics for each particular life choice: independence in choosing the ideal lifestyle, awareness and non-independence with an orientation to a favorable set of circumstances when choosing a career. When choosing a significant other, personally immature young people predominantly demonstrate low awareness and high selfsufficiency with an orientation toward a favorable combination of circumstances. Given the severity of the procedural characteristics of the choices of the ideal lifestyle, career and significant other among personally immature youth, these elections correspond to immature elections, which is especially indicative of choosing a significant other.

Thus, the specificity of the procedural characteristics of each of the life choices of young people is different depending on the types of personality maturity / immaturity and the type of choice itself. Thus, it has been established that in a series of life choices, personally mature young people are mature in their choice of the ideal of a way of life and significant other, and immature is their career choice. For personally immature youth, the maturity of a life choice has not been established, the elections of the ideal of lifestyle and career are moderately mature, and the choice of a significant other is immature.

\section{References}

1. S.T. Dzhaner'yan, D.I. Gvozdeva, Izvest of Southern Federal University. Pedagogical sciences, 10, 146-157 (2011)

2. S.T. Dzhaner'yan, Yu.V. Rashchupkina, News of universities. North Caucasus region, 1, (2015)

3. L.M. Mitina, Psychological support for choosing a profession (Psychological and Social Institute. Flint, Moscow, 1998)

4. Yu.V. Rashchupkina, Psychology of education in a multicultural space, 2, (2015)

5. N.V. Halina, Bulletin of the Russian State Pedagogical University named after A.I. Herzen, 102, 408-411 (2009) 